\title{
Comparative Mass Transfer Study of Basic and Acid Magenta Adsorption onto Natural Clay
}

\author{
Radia Yous ${ }^{1}$, Hakima Cherifi ${ }^{1}$, and Razika Khalladi ${ }^{2, *}$ \\ ${ }^{1}$ Laboratoire des Biomatériaux et des Phénomènes de Transferts LBPT, Université de Médéa, Médéa, 26000, Algérie \\ ${ }^{2}$ Laboratoire des Matériaux et Environnement LME Université de Médéa, Médéa, 26000, Algérie
}

*Corresponding author:

email:r_khalladi@yahoo.fr

Received: December 13, 2018

Accepted: February 27, 2019

DOI: $10.22146 /$ ijc. 41820

\begin{abstract}
In this work a comparative study of basic and acid magenta sorption on Algerian natural untreated clay was investigated using theoretical models for the following conditions $C_{0}(B M)=200 \mathrm{mg} / L, C_{0}(A M)=150 \mathrm{mg} / \mathrm{L}, V=500 \mathrm{~mL}, C_{B}(B M)=$ $1 g / L, T=22^{\circ} \mathrm{C}$. Adsorption mechanism of both dyes based on an intraparticle diffusion, external mass transfer, and kinetic models was examined. Statistical error functions regression coefficient $\left(R^{2}\right)$, the root mean square error (RMSE) and the average relative error deviation ARED were used to estimate the deviation between experimental and theoretical values. This work indicated that the experimental results obtained for both dyes fitted well the chosen models in the following order: External model of Boyd $<$ Kinetic model $<$ Urano and Tachikawa model $<$ External model of Weber and Morris $\leq$ Weber and Morris internal diffusion model. However, the calculated values of Biot number are 32.31 and 69.33 for acid magenta and basic magenta respectively, indicating that the adsorption of both dyes onto the same clay is initially controlled by external film diffusion at the first ten minutes. The adsorption capacity of the tested clay for both dyes is remarkable compared to other natural adsorbents. Where the best results were obtained for basic magenta $\left(q_{\text {exp }}=198.028 \mathrm{mg} \mathrm{g}^{-1}, R^{2}=0.992, A R E D=0.128\right.$ and $\left.R M S E=0.461\right)$.
\end{abstract}

Keywords: adsorption; intraparticle diffusion; dyes; montmorillonite; mass transfer

\section{- INTRODUCTION}

The preservation of the environment has become a major concern of all society, especially water resources. Thus, many researches were realized to develop new methods for the treatment of water loaded with organic pollutants such as dyes [1]. Dyes of type magenta are widely used in wool, nylon and textile dyeing. They can break down into carcinogenic aromatic amines under anaerobic conditions, so discharging these dyes into the water can cause serious problems such as allergic dermatitis, skin irritation and cancer [2]. These substances are excessively used to improve the dyeing process. However, their low biodegradability makes biological treatments difficult to apply. Many researchers have demonstrated the efficiency of adsorption on activated carbon to treat wastewater contaminated with dyes. This technique has been recognized as one of the best available methods [3-4]. Activated carbon has low initial costs, producing nontoxic by-products and rather simple in terms of design and operating [3,5-7]. The use of natural materials as adsorbents makes this method more attractive [3-4]. Researchers have shown the feasibility of different natural materials, such as chitosan [8], bentonite, zeolite, kaolin, and others [4,7,9]. In this work "an Algerian bentonite" has been chosen as a natural adsorbent. It is a type of clay that denotes a mineral powder consisting essentially of montmorillonite. This smectite is widely applied in many fields of industry including dyes [9], metals, and others [4]. In recent years, a special interest is granted to the use of this clay on different effluents, Ivanovich et al. have used composite material based on bentonite and hydroxyapatite montmorillonite to remove methylene blue from aqueous solution [10] and Hongfeng et al. [11] have examined the humic acid adsorption onto

Radia Yous et al. 
montmorillonite and kaolinite. Numerous materials were tested to eliminate acid, and basic magenta from an aqueous solution such as thorn apple leaves studied by Ameeth Basha et al. [12] and Laccase-Modified Zeolite examined by Ekrem et al. [13] to remove acid magenta. Many researches have used montmorillonite as an adsorbent to remove organic dyes from water because it is very available, low-cost, and easy to recycle [4,9-10]. However, the adsorption of acid and basic magenta on montmorillonite is only present in a limited number of literatures [14]. Furthermore, relatively few works discuss the rate-limiting steps involved in the adsorption process of these dyes [2-3].

The aim of this work is focused on the application of local clay for adsorbing anionic and cationic magenta present in wastewater of many textile manufactories. The adsorption mechanism of acid (AM) and basic magenta (BM) on this natural clay were investigated in order to evaluate its efficiency in the removal of both dyes from water. The determination of the rate controlling step in the process is very important in the design of the adsorption process. Therefore, in the present work, mass transfer studies were done to evaluate the rate-limiting step in the adsorption of both dyes from aqueous solution onto montmorillonite. Different mass transfer models were tested: External model of Boyd, External model of Weber and Morris, Urano and Tachikawa model, Weber and Morris internal diffusion model and first and secondorder kinetic models. A comparison based on the regression coefficient (R2), the root mean square error (RMSE) and the average relative error deviation (ARED) was realized between these models to deduce among them the well adapted to describe the kinetics of such a system. Also, the calculation of the Biot number was used as a determining factor to find the limiting-rate step in the overall adsorption mechanism.

\section{- EXPERIMENTAL SECTION}

\section{Materials}

\section{Adsorbent}

The adsorbent used in this work is a clay obtained from Maghnia (North West of Algeria). It is composed essentially of montmorillonite, which is a smectite $2: 1$.
Where an octahedral sheet of alumina is between two tetrahedral sheets of silica [15-16]. The negative surface charges of the montmorillonite layers are due to isomorphic substitutions of $\mathrm{Al}(\mathrm{III})$ for $\mathrm{Si}(\mathrm{IV})$ and $\mathrm{Mg}(\mathrm{II}) / \mathrm{Fe}$ (II) for $\mathrm{Al}(\mathrm{III})$ in its phyllosilicate structure [17]. The characteristics of Maghnia montmorillonite used in this study are shown in Table 1. The structural formula unit of this clay is: $\left(\mathrm{Si}_{8}\right)^{\mathrm{IV}}\left(\mathrm{Al}_{4-\mathrm{x}} \mathrm{Mg}_{\mathrm{x}}\right)^{\mathrm{VI}} \mathrm{O}_{20}(\mathrm{OH})_{4}$; with: $\mathrm{x}=0.5-0.9$.

\section{Adsorbates}

Acid magenta (AM), and basic magenta (BM) were used. Both dyes were purchased from PANREAC QUIMICA and used without any purification. Properties of these colorants are summarized in Table 2.

\section{Procedure}

\section{Adsorption process}

All experiments were carried out in batch. A mixture of adsorbent and adsorbate at a specific concentration were stirred with a magnetic stirrer (250 $\mathrm{rpm})$. The mass ratio of adsorbent to the volume of solution remains constant throughout the operation. Kinetic studies were realized by sampling solutions at regular time intervals. Determination of equilibrium dye concentration was carried out by UV spectrophotometer (UV-mini 1240 SHIMADZU) at a wavelength of $544 \mathrm{~nm}$ for acid magenta and $562 \mathrm{~nm}$ for Basic magenta. The adsorption capacity was calculated using the residual concentration deduced at equilibrium for initial concentrations ranging from (10 to 400$) \mathrm{mg} / \mathrm{L}$.

$$
\begin{aligned}
& \mathrm{q}=\left(\frac{\mathrm{C}_{0}-\mathrm{C}}{\mathrm{m}}\right) \mathrm{V} \\
& \mathrm{q}=\frac{\mathrm{C}_{0}-\mathrm{C}}{\mathrm{C}_{\mathrm{B}}}
\end{aligned}
$$

Table 1. Physico-chemical properties of clay

\begin{tabular}{lll}
\hline Parameters & Results & Unit \\
\hline $\begin{array}{l}\text { Apparent volumetric mass } \\
\text { Particle mean diameter }\end{array}$ & 1.11 & $\mathrm{~g} / \mathrm{cm}^{3}$ \\
$\begin{array}{l}\text { Specific surface area per unit volume } \\
\text { of solution }\end{array}$ & $4.0510^{-3}$ & $\mathrm{~cm}$ \\
Specific surface BET & $\mathrm{m}^{2} / \mathrm{m}^{3}$ \\
Micropores surface & 56.44 & $\mathrm{~m}^{2} / \mathrm{g}$ \\
pH & 30.89 & $\mathrm{~m}^{2} / \mathrm{g}$ \\
\hline
\end{tabular}


Table 2. Properties of acid and basic magenta [18-19]

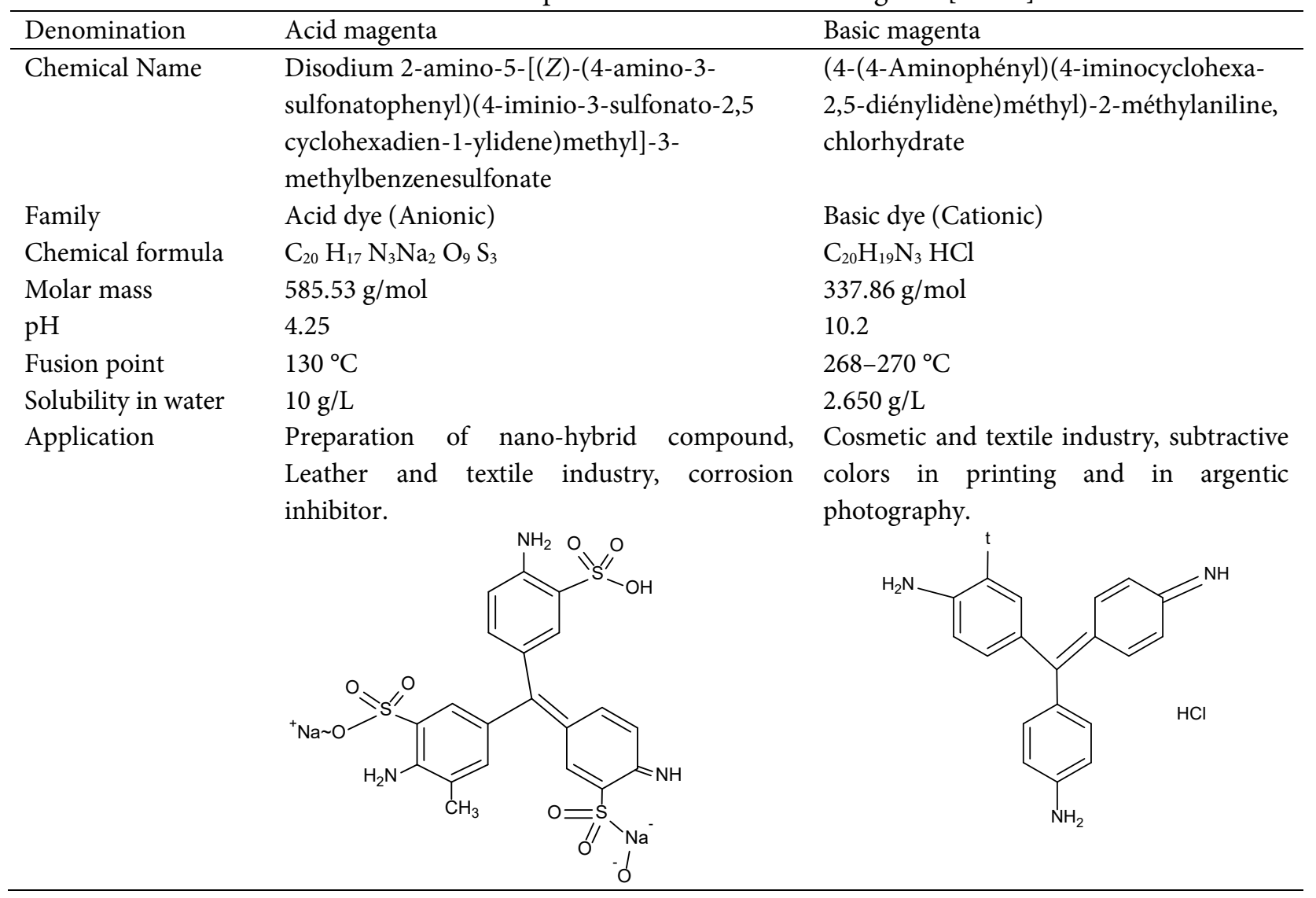

The adsorbed quantity noted $\mathrm{q}$ is given by Eq. (1) and (2). Where $\mathrm{C}_{0}(\mathrm{mg} / \mathrm{L}), \mathrm{C}(\mathrm{mg} / \mathrm{L}), \mathrm{m}(\mathrm{g})$ and $\mathrm{V}(\mathrm{mL})$ are respectively; the initial concentration, the concentration at time $t$, the mass of adsorbent and the volume of adsorbate. And the adsorbent concentration $C_{B}=m / V$.

\section{Statistical analysis}

In order to quantitatively compare the suitability of the kinetic models in fitting the experimental data, the coefficient of regression $\left(\mathrm{R}^{2}\right)$ and two error functions were used. The root mean square error (RMSE) and the average relative error deviation (ARED) (\%) calculated from Eq. (3) and Eq. (4) respectively [20]. The main advantage of the ARED function is the minimization of the fractional error distribution across the entire studied concentration range. Where $\mathrm{N}$ is the number of experimental data points, $\mathrm{q}_{\exp }(\mathrm{mg} / \mathrm{g})$ is the experimental adsorption quantity and $\mathrm{q}_{\text {cal }}(\mathrm{mg} / \mathrm{g})$ is the theoretically calculated adsorption quantity.

$$
\begin{aligned}
& \text { RMSE }=\sqrt{\frac{\sum\left(\mathrm{q}_{\exp }-\mathrm{q}_{\text {cal }}\right)^{2}}{\mathrm{~N}}} \\
& \text { ARED }=\frac{1}{\mathrm{~N}} \sum\left|\frac{\mathrm{q}_{\exp }-\mathrm{q}_{\text {cal }}}{\mathrm{q}_{\exp }}\right| \cdot 100
\end{aligned}
$$

\section{- RESULTS AND DISCUSSION}

\section{Kinetic Study}

The obtained results from the kinetic study of the adsorption of the basic and acid magenta on montmorillonite are illustrated in Fig. 1. The lecture of this figure shows that both curves can be partitioned in three parts for each dye. The first Part is linear for both dyes, from $t=0$ to $t=10 \mathrm{~min}$, In the case of the basic magenta (BM), after the first contact with the montmorillonite, the quantity adsorbed of dye increases remarkably with time. The adsorbed quantity of this dye is approximately $194 \mathrm{mg}$ of $\mathrm{BM} / \mathrm{g}$. However, in the case of 


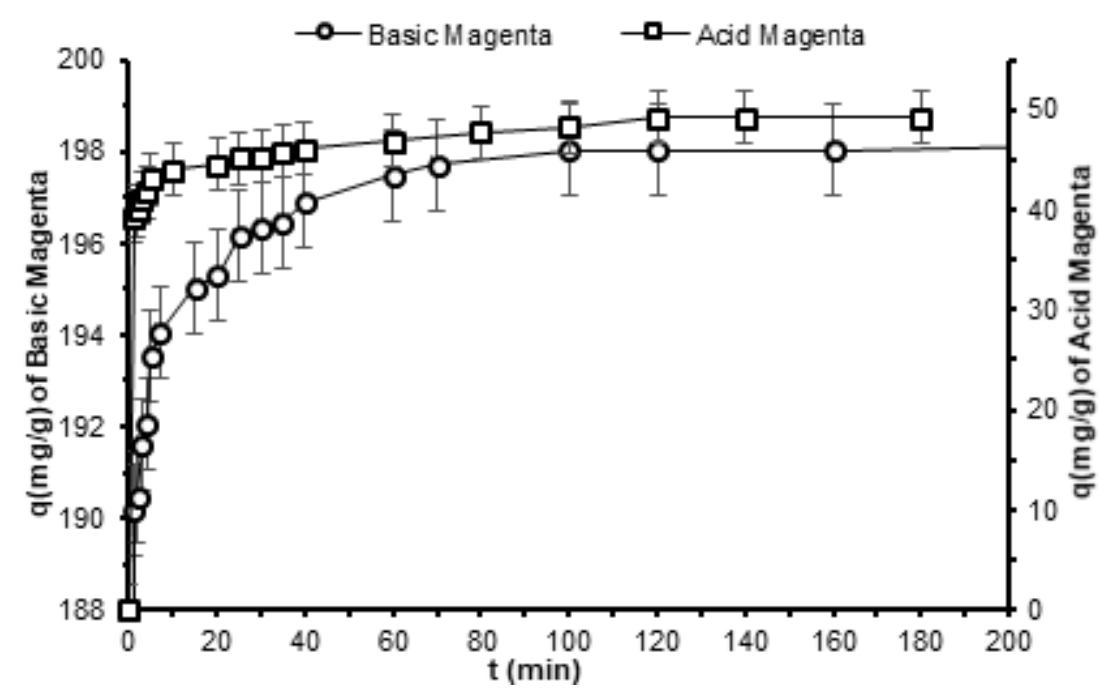

Fig 1. Kinetic adsorption of acid and basic magenta, $\mathrm{C}_{0(\mathrm{BM})}=200 \mathrm{mg} / \mathrm{L}, \mathrm{C}_{0(\mathrm{AM})}=150 \mathrm{mg} / \mathrm{L}, \mathrm{V}=500 \mathrm{~mL}, \mathrm{C}_{\mathrm{B}(\mathrm{BM})}=1 \mathrm{~g} / \mathrm{L}$, $\mathrm{T}=22^{\circ} \mathrm{C}$

the acid magenta (AM) the quantity adsorbed reached $43 \mathrm{mg} \mathrm{AM} / \mathrm{g}$.

The second part begins from $10 \mathrm{~min}$ until $\mathrm{t}=100 \mathrm{~min}$ for $\mathrm{BM}$ and $\mathrm{t}=120 \mathrm{~min}$ for AM. After a long time of contact, the quantity adsorbed on montmorillonite increases slowly for both dyes. This is due to the fact that the greater part of adsorption sites was occupied during the first stage. The third part is observed beyond $t=100 \mathrm{~min}$ and $\mathrm{t}=120 \mathrm{~min}$ for the basic and the acid magenta respectively. The last part of the adsorption curve shows a constant stage for both dyes. This behavior demonstrated that we already reached the end of the adsorption process. At this stage, equilibrium is reached, and we can determine the time of equilibrium and the quantity adsorbed at equilibrium $\left(\mathrm{q}_{\mathrm{e}}\right)$. When reading these results it was found that the adsorption of the basic magenta is more powerful than the adsorption of the acid. Indeed, the maximum quantity adsorbed at equilibrium $\left(\mathrm{q}_{\mathrm{e}}\right)$ of the $\mathrm{BM}(198 \mathrm{mg} / \mathrm{g})$ is higher than that of the AM $(48 \mathrm{mg} / \mathrm{g})$.

\section{Adsorption Mechanism}

In order to study the adsorption mechanism of the acid and basic magenta on montmorillonite, we have to distinguish between steps controlling the process: the external mass transfer step, the internal mass transfer step, and the adsorption step. Now it is well established, that the adsorption of dye on a porous solid occurs in four consecutive steps [21]: (1) Transport of the adsorbate from the bulk to the boundaries of the adsorbent; (2) Diffusion through the liquid film surrounding the adsorbent (film diffusion); (3) Transport of the adsorbate within the pores of the adsorbent (internal or intraparticle diffusion); (4) Adsorption of the adsorbate on the interior surface of the adsorbent.

Generally, the last step is very fast, and present a neglected resistance on the overall process rate. Thus, when calculating the coefficients of mass transfer, we will consider that the adsorption reaction rate is almost instantaneous. Also, in a well-agitated batch system, the external mass transfer resistance is neglected especially in large solution volume, the boundary layer surrounding the solid is much reduced, reducing the film diffusion resistance; hence, intraparticle diffusion is more likely to be the rate controlling step [23].

\section{External Mass Transfer Model (Film Diffusion)}

In the external mass transfer model, the concentration of the solute at the surface $\left(\mathrm{C}_{\mathrm{s}}\right)$ of the solid material depends on the diffusion through the boundary layer. Two mathematical models are studied. The first model was proposed by Weber and Morris [22] and Mc Kay and Poots [23-24]. The formula of this model is the following:

$\frac{\mathrm{dq}}{\mathrm{dt}}=\beta \mathrm{A}\left(\mathrm{C}-\mathrm{C}_{\mathrm{s}}\right)$ 
$\frac{\mathrm{dC}}{\mathrm{dt}}=-\beta \cdot S \cdot\left(\mathrm{C}-\mathrm{C}_{\mathrm{s}}\right)$

$S=\frac{6 C_{B}}{d_{p} \cdot \rho_{a p p}}$

In order to determine the external mass transfer coefficient $(\beta)$, we have assumed that the external resistance is not negligible. Indeed, it may be justified by the fact that at the first instants $(t=0)$ the concentration at the solid surface is almost equal to $C_{0}$. Where $A$ is the specific surface area of the particle per unit mass of the solution, and $S$ is the specific surface area of the particle per unit volume of the solution (Table 1). For boundary conditions, the former relation expressing the external mass transfer becomes.

$\left[\frac{\mathrm{dC} / \mathrm{C}_{0}}{\mathrm{dt}}\right]_{\mathrm{t} \rightarrow 0}=-\beta \mathrm{S}$

The second model adopted for the external mass transfer is Boyd's film-diffusion model. This model is usually used to describe the mechanism of the adsorption kinetics. When applied to external mass transfer, the linearized expression of this model is given by Eq. (9), where $\mathrm{Bt}$ is a mathematical function of the value $\left(\mathrm{q} / \mathrm{q}_{\mathrm{e}}\right)$ [25-26]. The obtained results for both dyes with the external model given by Weber and Morris are illustrated in Fig. 2(a). The calculated Bt values were plotted against time as shown in Fig. 2(b).

$\mathrm{Bt}=-0.4977-\log \left[1-\frac{\mathrm{q}}{\mathrm{q}_{\mathrm{e}}}\right]$

From Fig. 2(a) a linear part is found at the beginning of the $\mathrm{C} / \mathrm{C}_{0}$ curves $(<5 \mathrm{~min}$ ) for both dyes. Using the slope of this linear part allowed us to determine the values of external mass transfer coefficients $\beta$. Fig. 2(b) showed that the plots for the first ten minutes were linear but did not pass through the origin, indicating that, for both dyes, external mass transport mainly governs the rate-limiting adsorption process [27]. The calculated slope of the linear part of the curve $(B t=f(t))$ was used to determine the effective diffusion coefficient $D_{i}\left(\mathrm{~cm}^{2} / \mathrm{s}\right)$, where, $B$ is the slop calculated from the Fig. 2(b) and $d_{p}$ represents the diameter of the particle calculated by sieve analysis assuming uniform spherical particles [28-29]. The calculated $D_{i}$ values are given in Table 3.

The values of the external mass transfer coefficient and the effective diffusion coefficient $\mathrm{D}_{\mathrm{i}}$ obtained from each model for basic and acid magenta in the presence of montmorillonite are so different. However, both of
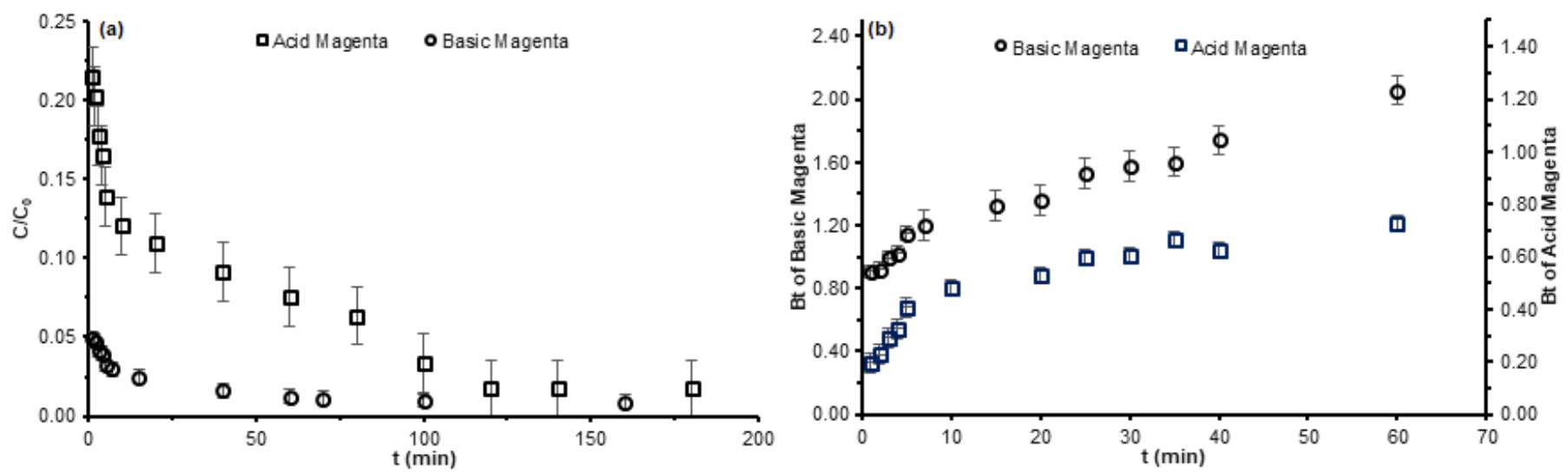

Fig 2. (a) Weber and Morris model, (b) Boyd model $\mathrm{C}_{0(\mathrm{BM})}=200 \mathrm{mg} / \mathrm{L}, \mathrm{C}_{0(\mathrm{Am})}=150 \mathrm{mg} / \mathrm{L}, \mathrm{V}=500 \mathrm{~mL}, \mathrm{C}_{\mathrm{B}(\mathrm{BM})}=1 \mathrm{~g} / \mathrm{L}$, $\mathrm{T}=22^{\circ} \mathrm{C}$

Table 3. Values of external mass transfer coefficients

\begin{tabular}{ccccccccc}
\hline \multirow{2}{*}{ Dyes } & \multicolumn{4}{c}{ Weber and Morris model } & \multicolumn{4}{c}{ Boyd's model } \\
\cline { 2 - 8 } & $\beta(\mathrm{cm} / \mathrm{s})$ & $\mathrm{R}^{2}$ & ARED & RMSE & $\mathrm{D}_{\mathrm{i}}\left(\mathrm{cm}^{2} / \mathrm{s}\right)$ & $\mathrm{R}^{2}$ & ARED & RMSE \\
\hline Acid magenta & $0.37 \times 10^{-7}$ & 0.99 & 1.8607 & 1.5114 & $0.09 \times 10^{-11}$ & 0.97 & 0.3457 & 31.6621 \\
Basic magenta & $0.26 \times 10^{-7}$ & 0.95 & 0.3678 & 0.2712 & $0.10 \times 10^{-11}$ & 0.92 & 0.1979 & 38.0044 \\
\hline
\end{tabular}


them expressed the presence of a non-negligible film resistance. The obtained values of $D_{i}$ are very low compared to those of $\beta$, meaning that the resistance of the film diffusion calculated by Weber and Morris model is greater than that found from Boyd's model. According to Karthikeyan et al. cited in [30] for boundary diffusion to be rate-limiting step, the value of the diffusion coefficient should be in the range $10^{-6}-10^{-8} \mathrm{~cm}^{2} / \mathrm{s}$. As a result, the external mass transfer by diffusion in the film can be a controlling step of the adsorption mechanism. A High value of $\mathrm{R}^{2}$ and lower RMSE and ARED were found for Weber and Morris model showing that this model fit well the experimental data (Table 3 ). The difference observed between the basic and acid magenta concerning $\beta$ value could be inferred to the cationic and anionic nature of these dyes. Additionally, the acid character of the colorant can greatly enhance the porosity of the montmorillonite and increases the total pore volume [31].

\section{Intraparticle Mass Transfer Model}

In order to make a more detailed study of the mass transfer during the adsorption process, we have endeavored to investigate the intraparticle diffusion using two models. In this work, the chosen models refer to the theories developed by Weber and Morris [22] and Urano and Tachikawa [28]. The internal diffusion will take place when the adsorbent texture contains pores, and substrate entity of smaller size can migrate inside pores. According to the model proposed by Weber and Morris for the intraparticle diffusion, the coefficient of diffusion $D_{w}$ $\left(\mathrm{cm}^{2} \mathrm{~s}^{-1}\right)$ for basic and acid magenta are calculated using the following two equations [22].

$\mathrm{q}=\mathrm{K}_{\mathrm{w}} \mathrm{t}^{5}+\mathrm{I}$

$\mathrm{K}_{\mathrm{w}}=\left(\frac{12 \mathrm{q}_{\mathrm{e}}}{\mathrm{d}_{\mathrm{p}}}\right)\left(\frac{\mathrm{D}_{\mathrm{w}}}{\pi}\right)^{0.5}$

$-\log _{10}\left[1-\left(\frac{\mathrm{q}}{\mathrm{q}_{\mathrm{e}}}\right)^{2}\right]=\frac{4 \pi^{2} \mathrm{D}_{\mathrm{u}} \mathrm{t}}{2.3 \mathrm{~d}_{\mathrm{p}}^{2}}$

Urano and Tachikawa have proposed another model given by Eq. (13) where $D_{u}$ is the intraparticle diffusion coefficient $\left(\mathrm{cm}^{2} \mathrm{~s}^{-1}\right)$. These coefficients were determined, assuming that the external resistance is negligible and that the adsorption of the two dyes on montmorillonite is controlled only by the internal diffusion. The results are presented in Fig. 3.

Fig. 3(a), shows that both dyes curves have the same shape and each of them can be subdivided into three parts. The first part is linear and exhibits an initial slope, representing a fast mass transfer by diffusion throughout the macrospores (>50 nm). Where the dye entities can penetrate quickly and easily within the pores. However, the second part of the kinetic curve exhibits a lower slop. This step can be explained by the presence of a slower mass transfer through the mesopores $(2-50 \mathrm{~nm})$. The third part of the plot reflected a very slow diffusion step which is associated probably with adsorption on the micropores $(<2 \mathrm{~nm})$ [29]. In addition, the plots in Fig. 3(a) do not pass through the origin; this is indicative of an external film
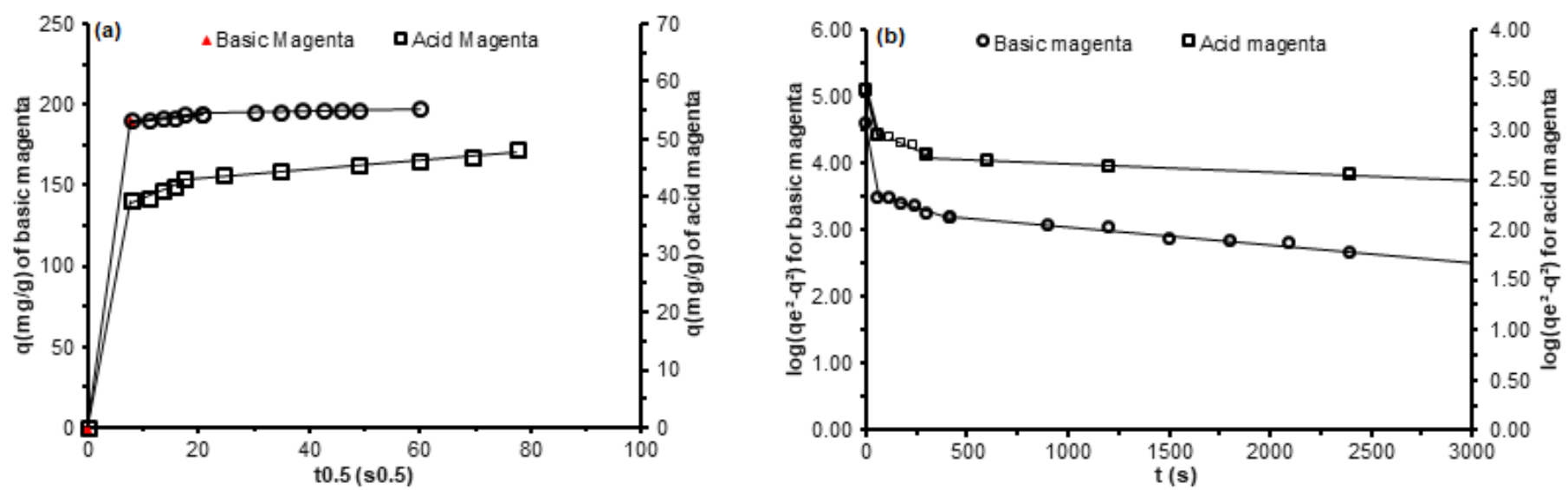

Fig 3. (a) Internal Weber and Morris model, (b) model of Urano and Tachikawa $C_{0(\mathrm{BM})}=200 \mathrm{mg} / \mathrm{L}, \mathrm{C}_{0(\mathrm{AM})}=150 \mathrm{mg} / \mathrm{L}$, $\mathrm{V}=500 \mathrm{~mL}, \mathrm{C}_{\mathrm{B}(\mathrm{BM})}=1 \mathrm{~g} / \mathrm{L}, \mathrm{T}=22^{\circ} \mathrm{C}$ 
mass transfer or boundary layer control. For most systems reported in the literature, film resistance in the initial stages of the sorption process was detected. However, the concentration gradient decreases quickly and so its influence is usually limited to the early stages of adsorption [23-24]. The presence of these three stages of diffusion can be explained by the heterogeneous surface of the adsorbent deduced from the important value of the micropores surface $\left(30.89 \mathrm{~m}^{2} / \mathrm{g}\right)$ compared to the specific surface $\left(56.44 \mathrm{~m}^{2} / \mathrm{g}\right)$. Fig. 3(b) represents the kinetic curves using the model of Urano and Tachikawa for the basic and acid magenta. The obtained plots are similar to those of Weber and Morris model, presenting three parts of different slopes. A fast stage followed by two other slower steps. The determination of the slopes from the kinetic curves given in Fig. 3, allowed us to determine the intraparticle diffusion coefficients $D_{w}$ and $D_{u}$. The obtained values for both dyes during the adsorption process are given in Table. 4.

The comparison between the values of the intraparticle diffusion coefficients $D_{w}$ and $D_{u}$ shows that the obtained values for the basic and acid magenta are approximate of the same order, the range $10^{-11}-10^{-13} \mathrm{~cm}^{2} / \mathrm{s}$ [30]. This indicates that the adsorption of both colorants is highly influenced by the intraparticle diffusion resistance. From Table 4, low RMSE and low ARED values indicated that the Weber and Morris model is more representative than Urano and Tachikawa for the adsorption of basic and acid magenta on montmorillonite ( $\mathrm{R}^{2}$ is similar for both models). In addition, the values of the intraparticle diffusion coefficients $\left(D_{w}, D_{u}\right)$ are lower in magnitude than the external mass transfer coefficients $\beta$ given in Table 3. This difference can be explained by the presence of an important resistance in the pores may be due to the electrostatic interactions between charged molecules-molecule or charged molecules and adsorbent surface [31].

\section{Kinetic Models}

The experimental results were plotted using two different kinetic models. The first-order model of Lagergren [32], and the second-order model proposed by Ho and McKay [29] and Aksu [33] expressed by the following relations. Where $k_{1}$ and $k_{2}$ are the first and the second-order rate constants respectively.

$$
\begin{aligned}
& -\log _{10}\left[\frac{\left(\mathrm{q}_{\mathrm{e}}-\mathrm{q}\right)}{\mathrm{q}_{\mathrm{e}}}\right]=\frac{\mathrm{k}_{1}}{2.3} \mathrm{t} \\
& \frac{1}{\mathrm{q}_{\mathrm{e}}-\mathrm{q}}=\frac{1}{\mathrm{q}_{\mathrm{e}}}-\mathrm{k}_{2} \mathrm{t}
\end{aligned}
$$

The corresponding curves obtained for basic and acid magenta are presented in Fig. 4 and 5 respectively. The shape of the obtained curves for both dyes shows that the adsorption process fits well the pseudo secondorder model. This result is in accordance with that obtained by Zarei [34], and Simonin [35]. The values of the rate constants and the correlation coefficients for both dyes are summarized in Table 5 .

Table 5 shows that for the first-order kinetic model the quantity adsorbed at equilibrium determined experimentally is so different from that calculated. Thus, the adsorption kinetic of the BM and AM doesn't follow this model. However, the adsorbed quantity at equilibrium determined experimentally is closer to that

Table 4. The intraparticle diffusion coefficients $D_{w}$ and $D_{u}$ for basic and acid magenta

\begin{tabular}{clllllll}
\hline & & \multicolumn{3}{c}{ Acid magenta } & \multicolumn{3}{c}{ Basic magenta } \\
\cline { 3 - 7 } & & Macrospore & Mesopore & Micropore & Macrospore & Mesopore & Micropore \\
\hline \multirow{3}{*}{ Weber and } & $\mathrm{D}_{\mathrm{W}}\left(\mathrm{cm}^{2} / \mathrm{s}\right)$ & $2.29 \times 10^{-12}$ & $0.20 \times 10^{-13}$ & $0.01 \times 10^{-14}$ & $3.35 \times 10^{-12}$ & $0.03 \times 10^{-14}$ & $0.02 \times 10^{-14}$ \\
Morris & 1.00 & 0.98 & 0.97 & 1.00 & 0.95 & 0.97 \\
& $\mathrm{ARED}$ & & 0.0631 & & & 0.5874 & \\
& $\mathrm{RMSE}$ & & 1.1081 & & & 2.3084 & \\
& $\mathrm{D}_{\mathrm{U}}\left(\mathrm{cm}^{2} / \mathrm{s}\right)$ & $0.75 \times 10^{-12}$ & $0.91 \times 10^{-12}$ & $0.81 \times 10^{-13}$ & $0.19 \times 10^{-11}$ & $0.91 \times 10^{-12}$ & $0.30 \times 10^{-12}$ \\
Urano and & $\mathrm{R}^{2}$ & 1.00 & 0.98 & 0.99 & 1.00 & 0.95 & 0.99 \\
Tachikawa & $\mathrm{ARED}$ & & 5.1841 & & & 1.3826 & \\
& $\mathrm{RMSE}$ & & 5.5114 & & & 6.2347 & \\
\hline
\end{tabular}

Radia Yous et al. 


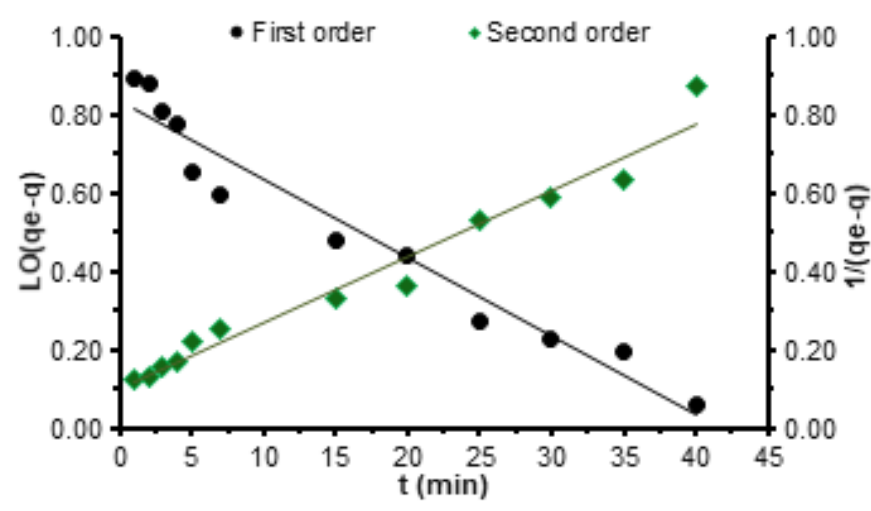

Fig 4. Kinetic models for basic magenta, $\mathrm{C}_{0(\mathrm{BM})}=$ $200 \mathrm{mg} / \mathrm{L}, \mathrm{C}_{0(\mathrm{AM})}=150 \mathrm{mg} / \mathrm{L}, \mathrm{V}=500 \mathrm{~mL}, \mathrm{C}_{\mathrm{B}(\mathrm{BM})}=1 \mathrm{~g} / \mathrm{L}$, $\mathrm{T}=22{ }^{\circ} \mathrm{C}$

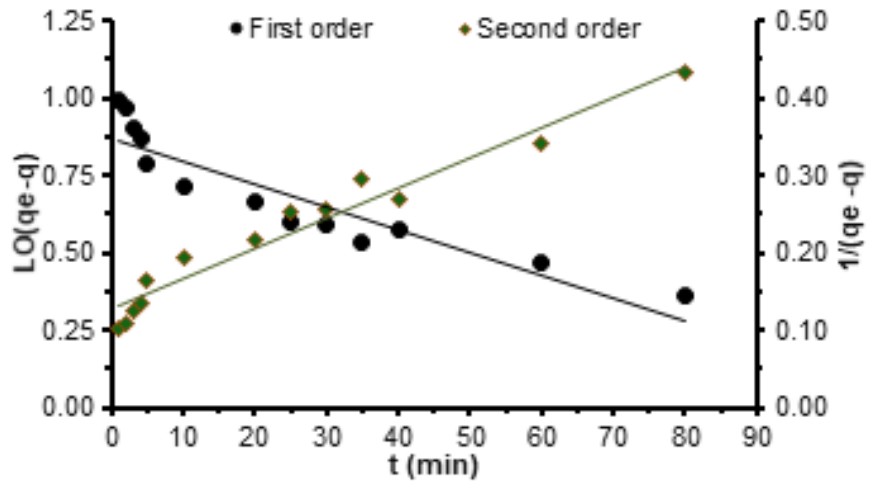

Fig 5. Kinetic models for acid magenta, $\mathrm{C}_{0(\mathrm{BM})}=$ $200 \mathrm{mg} / \mathrm{L}, \mathrm{C}_{0(\mathrm{AM})}=150 \mathrm{mg} / \mathrm{L}, \mathrm{V}=500 \mathrm{~mL}, \mathrm{C}_{\mathrm{B}(\mathrm{BM})}=1 \mathrm{~g} / \mathrm{L}$, $\mathrm{T}=22^{\circ} \mathrm{C}$

Table 5. Values of acid and basic magenta adsorption rate constant on montmorillonite

\begin{tabular}{lll}
\hline & First order & Pseudo-second order \\
\hline & $\mathrm{K}_{1}\left(\mathrm{~min}^{-1}\right)=0.0072$ & $\mathrm{~K}_{2}\left(\mathrm{~g} \mathrm{mg}^{-1} \mathrm{~min}^{-1}\right)=0.0395$ \\
& $\mathrm{R}^{2}=0.881$ & $\mathrm{R}^{2}=0.969$ \\
Acid magenta & $\mathrm{q}_{\mathrm{e}(\exp )}\left(\mathrm{mg} \mathrm{g}^{-1}\right)=49.139$ & $\mathrm{q}_{\mathrm{e}(\exp )}\left(\mathrm{mg} \mathrm{g}^{-1}\right)=49.139$ \\
& $\mathrm{q}_{\mathrm{e}(\mathrm{cal})}\left(\mathrm{mg} \mathrm{g}^{-1}\right)=2.4353$ & $\mathrm{q}_{\mathrm{e}(\mathrm{cal})}\left(\mathrm{mg} \mathrm{g}^{-1}\right)=46.729$ \\
& ARED $=5.079$ & ARED $=0.405$ \\
& $\mathrm{RMSE}=3.658$ & $\mathrm{RMSE}=0.952$ \\
\hline \multirow{5}{*}{ Basic magenta } & $\mathrm{K}_{1}\left(\mathrm{~min}^{-1}\right)=0.02$ & $\mathrm{~K}_{2}\left(\mathrm{~g} \mathrm{mg}^{-1} \mathrm{~min}^{-1}\right)=0.017$ \\
& $\mathrm{R}^{2}=0.950$ & $\mathrm{R}^{2}=0.992$ \\
& $\mathrm{q}_{\mathrm{e}(\exp )}\left(\mathrm{mg} \mathrm{g}^{-1}\right)=198.028$ & $\mathrm{q}_{\mathrm{exp}}\left(\mathrm{mg} \mathrm{g}^{-1}\right)=198.028$ \\
& $\mathrm{q}(\mathrm{cal})\left(\mathrm{mg} \mathrm{g}^{-1}\right)=58.82$ & $\mathrm{q}_{\mathrm{e}(\mathrm{cal})}\left(\mathrm{mg} \mathrm{g}^{-1}\right)=196.078$ \\
& $\mathrm{ARED}=1.280$ & $\mathrm{ARED}=0.128$ \\
& $\mathrm{RMSE}=3.093$ & $\mathrm{RMSE}=0.461$ \\
\hline
\end{tabular}

calculated using the second-order kinetic model. Hence, this former model applies well to describe the studied system. The obtained values of the coefficient $\mathrm{R}^{2}$ and error functions (ARED, RMSE) are significant for the second order model.

\section{Comparison between Different Kinetic Models}

In order to find the potential resistance controlling the overall adsorption mechanism, we have compared the experimental dye concentration in the solid material $\mathrm{C}_{\mathrm{s}}$ with those calculated by the kinetic and diffusional models. The following Fig. 6 and 7 represent the plot of experimental and theoretical $\mathrm{C}_{\mathrm{S}}$ versus time.

According to Fig. 6 and 7, the studied kinetic models are approaching the experimental results for both colorants in the following order: External model of Boyds
$<$ Kinetic model < Urano and Tachikawa model < External model of Weber and Morris $\leq$ Weber and Morris internal diffusion. So, the calculated values of $\mathrm{C}_{s}$ using the internal model of Weber and Morris fitted well the experimental results. However, it should be noted that the external and internal Weber and Morris plots are almost superposed on experimental data in the first part of the adsorption process $(0-10 \mathrm{~min})$. To resolve this confusing state, Biot number was calculated. Biot number (Biot) is a dimensionless number that relates the external mass transfer resistance with the internal mass transfer resistance [21]. It can be used as a determining factor for finding the rate controlling step using the values of the internal and external diffusion models of Weber and Morris ( $D_{w}$ for macropores diffusion). The calculated values of Biot number using Eq. (16) are 32.31 


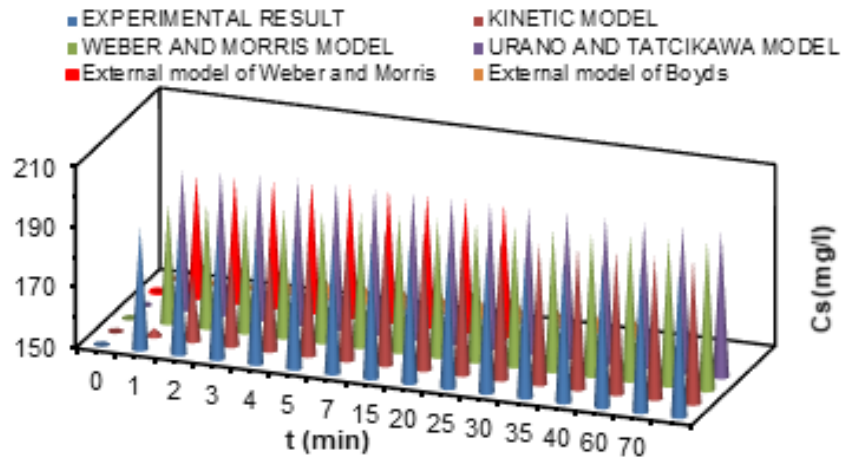

Fig 6. Comparison between different kinetic models for basic magenta at initial concentration $200 \mathrm{mg} / \mathrm{L}, \mathrm{T}=22^{\circ} \mathrm{C}$

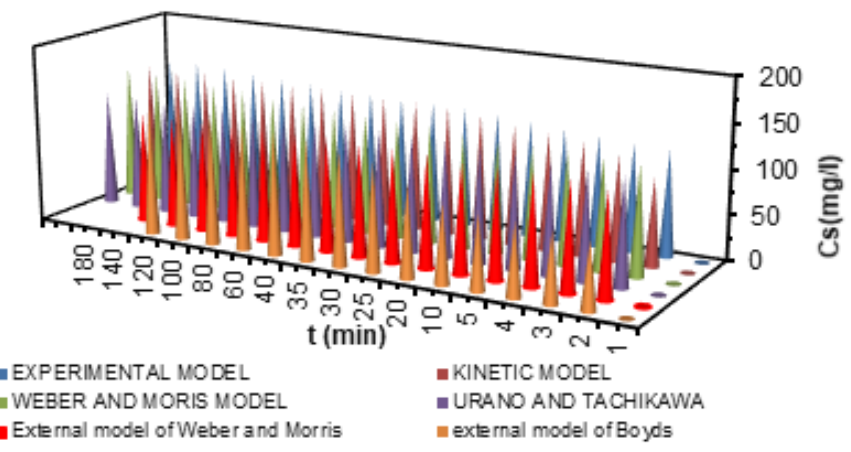

Fig 7. Comparison between different models for acid magenta at initial concentration $150 \mathrm{mg} / \mathrm{L}, \mathrm{T}=22{ }^{\circ} \mathrm{C}$

Table 6. Adsorption capacity of acid and basic magenta given by literature

\begin{tabular}{|c|c|c|c|}
\hline Adsorbents & Dyes & $\mathrm{q}_{\mathrm{e}}(\mathrm{mg} / \mathrm{g})$ & Ref \\
\hline Montmorillonite & Basic magenta & 198 & This study \\
\hline $\mathrm{H}_{2} \mathrm{SO}_{4}$ activated immature Gossypium hirsutum seeds & Basic magenta & 39.17 & [3] \\
\hline peat-resin particle & Basic magenta & 39.5 & {$[36]$} \\
\hline leaves of Thorn apple & Basic magenta & 120 & {$[12]$} \\
\hline Rice husk carbon & Basic magenta & 178 & {$[35]$} \\
\hline Montmorillonite & Acid magenta & 48 & This study \\
\hline Montmorillonite & Acid magenta & 16.6 & {$[14]$} \\
\hline $\mathrm{TiO}_{2} /$ schorl composite catalyst & Acid magenta & 9.23 & [37] \\
\hline Carbon Alumina Composite Pellet & Acid magenta & 39.5 & {$[18]$} \\
\hline Laccase-Modified Zeolite & Acid magenta & 31 & {$[13]$} \\
\hline
\end{tabular}

for acid magenta and 69.33 for the basic. The obtained values are less than 100 . This indicates that the adsorption of both dyes onto the chosen clay is initially controlled by film diffusion at the first ten minutes.

Biot $=\frac{\beta \cdot d_{p}}{D_{w}}$

\section{Efficiency of the Algerian Clay in the Removal of Basic and Acid Magenta}

In order to evaluate the efficiency of the Algerian clay used as a natural adsorbent in this study, a comparison based on the maximum adsorption capacity of $\mathrm{AM}$ and BM with different adsorbents reported in the literature was made. The results are listed in Table 6 . Compared with different adsorbents the Algerian clay used in this study could be considered as a promising natural material to remove basic and acid magenta from aqueous systems. The tested clay adsorption capacity of basic and acid magenta is greater than that of all other adsorbents.

\section{- CONCLUSION}

The investigation of the basic and acid magenta adsorption on montmorillonite showed that the experimental results obtained for both dyes fitted well the studied models in the following order: External model of Boyd < Kinetic model < External model of Weber and Morris < Urano and Tachikawa model < Weber and Morris internal diffusion model for acid magenta. However, for basic magenta the order is the following: External model of Boyds $<$ Kinetic model $<$ Urano and Tachikawa model $<$ External model of Weber and Morris < Weber and Morris internal diffusion model. In addition, this study indicated that the montmorillonite used in this study could be considered as a promising adsorbent to remove basic and acid 
magenta from effluent water. The adsorption capacity obtained for montmorillonite is very significant, especially for basic dyes. The adsorption kinetics appears to be pseudo-second order, and the main resistance limiting the sorption rate is the intraparticle diffusion step as indicated by the values of the Biot number.

\section{- ACKNOWLEDGMENTS}

The authors wish to thank the Algerian society of mineral and nonferrous products, ENOF Maghnia (Algeria) for their support by providing us with the adsorbent used in this study.

\section{- REFERENCES}

[1] Ben Mansour, H., Boughzala, O., Dridi, D., Barillier, D., Chekir-Ghedira, L., and Mosrati, R., 2011, Les colorants textiles sources de contamination de l'eau: CRIBLAGE de la toxicité et des méthodes de traitement, Rev. Sci. Eau, 24 (3), 209-238.

[2] Shanmugam, D., and Murugappan, A., 2016, Adsorption of basic magenta using fresh water algae and brown marine seaweed: Characterization studies and error analysis, J. Eng. Sci. Technol., 11 (10), 14211436.

[3] Sivarajasekar, N., and Baskar, R., 2014, Adsorption of basic magenta II onto $\mathrm{H}_{2} \mathrm{SO}_{4}$ activated immature Gossypium hirsutum seeds: Kinetics, isotherms, mass transfer, thermodynamics and process design, Arabian J. Chem., 280.

[4] Ahmad, A., Mohd-Setapar, S.H., Chuong, C.S., Khatoon, A., Wani, W., Kumar, R., and Rafatullah, M., 2015, Recent advances in new generation dye removal technologies: Novel search of approaches to reprocess waste water, $R S C A d v$., 5 (39), 30801-30818.

[5] Sivarajasekar, N., Mohanraj, N., Sivamani, S., Moorthy, I.G., Kothandan, R., and Muthusaravanan, S., 2017, Comparative modeling of fluoride biosorption onto waste Gossypium hirsutum seed microwave-bichar using response surface methodology and artificial neural networks, International Conference on Intelligent Computing, Instrumentation and Control Technologies (ICICICT),
6-7 July 2017, Kannur, India, 1631-1635.

[6] Sivarajasekar, N., Mohanraj, N., Sivamani, S., Marand, J.P., Moorthy, I.G., and Balasubramani, K., 2018, Statistical optimization studies on adsorption of ibuprofen onto Albizialebbeck seed pods activated carbon prepared using microwave irradiation, Mater. Today: Proc., 5 (2), 7264-7274.

[7] Vakili, M., Rafatullah, M., Salamatini, B., Abdullah, A., Ibrahim, M.H., Kok Bing, T., Gholami, Z., and Amouzgar, P., 2014, Application of chitosan and its derivatives as adsorbents for dye removal from water and wastewater: A review, Carbohydr. Polym., 113, 115-130.

[8] Rafatullah, M., Sulaiman, O., Hashim, R., and Ahmad A., 2010, Adsorption of methylene blue on low-cost adsorbents: A review, J. Hazard. Mater., 177 (1-3), 70-80.

[9] Ayari, F., Srasra, E., and Trabelsi-Ayadi, M., 2007, Retention of organic molecule "quinalizarin" by bentonitic clay saturated with different cations, Desalination, 206 (1-3), 499-506.

[10] Vezentsev, A.I., Thuy, D.M., GoldovskayaPeristaya, L.F., and Glukhareva, N.A., 2018, Adsorption of methylene blue on the composite sorbent based on bentonite-like clay and hydroxyapatite, Indones. J. Chem., 18 (4), 733-741.

[11] Chen, H., Koopal, L.K., Xiong, J., Avena, M., and Tan, W., 2017, Mechanisms of soil humic acid adsorption onto montmorillonite and kaolinite, $J$. Colloid Interface Sci., 504, 457-467.

[12] Basha, I.A., Nagalakshmi, R., and Shanthi, T., 2016, Removal of Congo red and magenta dyes from industrial waste water by thorn apple leaf powder, Int. J. Chem. Sci., 14 (S1), 57-64.

[13] Kalkan, E., Nadaroglu, H., Celebi, N., Celik, H., and Tasgin E., 2015, Experimental study to remediate acid fuchsin dye using laccase-modified zeolite from aqueous solutions, Pol. J. Environ. Stud., 24 (1), 115-124.

[14] Elsherbiny, A.S., 2013, Adsorption kinetics and mechanism of acid dye onto montmorillonite from aqueous solutions: Stopped-flow measurements, 
Appl. Clay. Sci., 83-84, 56-62.

[15] Lahodny-Sarc, O., and Khalaf, H., 1994, Some considerations of the influence of source clay material and synthesis conditions on the properties of Al-pillared clays, Appl. Clay. Sci., 8 (6), 405-415.

[16] Bhattacharyya, K., and Gupta, S., 2008, Adsorption of a few heavy metals on natural and modified kaolinite and montmorillonite: A review, $A d v$. Colloid Interface Sci., 140 (2), 114-131.

[17] Nagelschmidt, G., 1939, The identification of minerals in soil colloids, J. Agric. Sci., 29 (4), 477-501.

[18] Dutta, M., and Basu, J.K., 2014, Fixed-bed column study for the adsorptive removal of acid fuchsin using carbon-alumina composite pellet, Int. J. Environ. Sci. Technol., 11 (1), 87-96.

[19] Yu, J., Wang, L., Chi, R., Zhang, Y., Xu, Z., and Guo, J., 2013, Removal of cationic dyes: Basic magenta and methylene blue from aqueous solution by adsorption on modified loofah, Res. Chem. Intermed., 39 (8), 3775-3790.

[20] Cherifi, H., Hanini, S., and Bentahar, F., 2009, Adsorption of phenol from wastewater using vegetal cords as a new adsorbent, Desalination, 244 (1-3), 177-187.

[21] Girish, C.R., and Murty, V.R., 2016, Mass transfer studies on adsorption of phenol from wastewater using Lantana camara, forest waste, Int. J. Chem. Eng., 2016, 5809505.

[22] Weber, W.J., and Morris, J.C., 1962, "Advances in water pollution research: Removal of biologically resistant pollutant from waste water by adsorption" in Proceedings of the International Conference on Water Pollution Symposium, vol. 2, Pergamon Press, Oxford, UK, 231-266.

[23] McKay, G., and Poots, V.J.P., 1980, Kinetics and diffusion processes in color removal from effluent using wood as an adsorbent, J. Chem. Technol. Biotechnol., 30 (1), 279-292,

[24] McKay, G., Blair, HS., and Fidon, A., 1986, “Sorption of Metal Ions by Chitosan" in Immobilisation of Ions by Bio-sorption, Eds., Heccles, H., and Hunt, S., Ellis Horwood, Chichester, UK., 59-69.
[25] Boyd, G.E., Adamson, A.W., and Myers, L.S., 1947, The exchange adsorption of ions from aqueous solutions by organic Zeolites. II. Kinetics, J. Am. Chem. Soc., 69 (11), 2836-2848.

[26] Sankar, M., Sekaran, G., Sadulla, S., and Ramasami, T., 1999, Removal of diazo and triphenyl methane dyes from aqueous solutions through an adsorption process, J. Chem. Technol. Biotechnol., 74 (4), 337344.

[27] Lee, C.K., Liu, S.S., Juang, L.C., Wang, C.C., Lin, K.S., and Lyu, M.D., 2007, Application of MCM-41 for dyes removal from wastewater, J. Hazard. Mater., 147, 997-1005.

[28] Urano, K., and Tachikawa, H., 1991, Process development for removal and recovery of phosphorus from wastewater by a new adsorbent-2. Adsorption rates and breakthrough curves, Ind. Eng. Chem. Res., 30, 1897-1899.

[29] Ho, Y.S., and McKay, G., 1999, Pseudo-second order model for sorption process, Process Biochem., 34 (5), 451-465.

[30] Karthikeyan, S., Sivakumar, B., and Sivakumar, N., 2010, Film and pore diffusion modeling for adsorption of reactive red 2 from aqueous solution on to activated carbon prepared from bio-diesel industrial waste, E-J. Chem., 7 (S1), S175-S184.

[31] Krupskaya, V.V., Zakusin, S.V., Tyupina, E.A., Dorzhieva, O.V., Zhukhlistov, A.P., Timofeeva, M.N., and Belousov, P.E., 2017, Experimental study of montmorillonite structure and transformation of its properties under treatment with inorganic acid solutions, Minerals, 7 (4), 49.

[32] Lagergren, S., 1898, Zur theorie der sogenannten adsorption geloöster stoffe, Kungl. Svenska Vetenskapsakad. Handl., 24 (4), 1-39.

[33] Aksu, Z., 2001, Equilibrium and kinetics modelling of cadmium (II) biosorption by C. vulgaris in batch system: Effect of temperature, Sep. Purif. Technol., 21 (3), 285-294.

[34] Zarei, S., Sadeghi, M., and Bardajee, G.R., 2018, Dye removal from aqueous solutions using novel nanocomposite hydrogel derived from sodium 
montmorillonite nanoclay and modified starch, Int. J. Environ. Sci. Technol, 15 (11), 2303-2316.

[35] Simonin, J.P., 2016, On the comparison of pseudofirst order and pseudo-second order rate laws in the modeling of adsorption kinetics, Chem. Eng. J., 300, 254-263.

[36] Sun, Q., and Yang, L., 2003, The adsorption of basic dyes from aqueous solution on modified peat-resin particle, Water Res., 37 (7), 1535-1544.

[37] Xu, H.Y., Zheng, Z., and Mao, G.J., 2010, Enhanced photocatalytic discoloration of acid fuchsine wastewater by $\mathrm{TiO}_{2} /$ schorl composite catalyst, $J$. Hazard. Mater., 175 (1-3), 658-665. 